Kyu Joo Park • Ki-Hyuk Shin • Ja-Lok Ku

Tae-Joon Cho • Sang Hoon Lee • In Ho Choi

Christophe Phillipe - Anthony P. Monaco

Daniel E. Porter • Jae-Gahb Park

\title{
Germline mutations in the EXT1 and EXT2 genes in Korean patients with hereditary multiple exostoses
}

Received: December 4, 1998 / Accepted: March 26, 1999

\begin{abstract}
Hereditary multiple exostoses (EXT) is an autosomal dominantly inherited disease characterized by the formation of cartilage-capped prominences (exostoses) that develop from the juxtaepiphyseal regions of the long bones. Recently, EXT1 and EXT2 genes were cloned and germline mutations of $E X T 1$ and $E X T 2$ were identified in EXT families. In this study, we performed a mutational analysis of EXT1 and EXT2 genes in eight unrelated Korean EXT families by polymerase chain reaction (PCR)-single strand conformation polymorphism (SSCP) analysis followed by direct DNA sequencing. As a result, we were able to identify one family (SNU-OC3) with the EXT1 mutation and another family (SNU-OC15) with the EXT2 mutation. The EXT1 mutation was a 10-bp deletion at the $3^{\prime}$ end of exon 5 (CTAATTTAGg) including the splice site of this exon. The EXT2 mutation identified in the SNU-OC15 family was a missense mutation at codon 85 of exon 2 ( $\underline{T} G C \rightarrow \underline{C G C)}$, resulting in an amino acid change from cysteine to arginine. This missense mutation cosegregated with the disease phenotype in this family, suggesting that it is the diseasecausing mutation. These two mutations identified in EXT1 and $E X T 2$ are novel ones.
\end{abstract}

K.J. Park · K.-H. Shin · J.-L. Ku · J.-G. Park $(\varangle)$

Korean Hereditary Tumor Registry, Laboratory of Cell Biology,

Cancer Research Center and Cancer Research Institute, Seoul

National University College of Medicine, 28 Yongon-dong,

Chongno-gu, Seoul 110-744, Korea

Tel. +82-2-760-3380; Fax +82-2-742-4727

e-mail: jgpark@plaza.snu.ac.kr

T.-J. Cho $\cdot$ S.H. Lee $\cdot$ I.H. Choi

Department of Orthopedic Surgery, Seoul National University

College of Medicine, Seoul, Korea

C. Philippe

Laboratore de Génétique, Centre Hospitalier Universitare, Nancy, France

A.P. Monaco

The Wellcome Trust Centre for Human Genetics, University of Oxford, Oxford, U.K.

D.E. Porter

Nuffield Department of Orthopedic Surgery, University of Oxford,

Oxford, U.K.
Key words $E X T 1 \cdot E X T 2 \cdot$ Germline mutation

\section{Introduction}

Hereditary multiple exostoses (EXT) is an autosomal dominantly inherited disease characterized by the development of cartilage-capped exostoses (osteochondromas) from the juxtaepiphyseal regions of the long bones. Exostoses may be apparent at birth, and they are usually evident by the end of the first decade of life in $80 \%$ of individuals (Solomon, 1963). Approximately two-thirds of the affected individuals with EXT have orthopedic complications (Wicklund et al. 1995). But the most serious complication of EXT is malignant degeneration of benign exostoses to chondrosarcoma or to some other sarcomas (Schmale et al. 1994).

EXT is a genetically heterogeneous disease. Linkage analysis has demonstrated that EXT is caused by at least three different genes, EXT1 on chromosome 8q23-q24 (Cooke et al. 1993), EXT2 on chromosome 11p11-p12 (Wu et al. 1994; Wuyts et al. 1995), and EXT3 on chromosome 19p (Le Merrer et al. 1994). However, it now appears that most EXT families are linked to EXT1 and EXT2 loci (Halloran-Blanton et al. 1996; Raskind et al. 1998). Recently, the EXT1 and EXT2 genes have been cloned and germline mutations of these genes confirmed in EXT families (Ahn et al. 1995; Stickens et al. 1996; Wuyts et al. 1996). EXT1 and EXT2 show homology to each other and define a new family of related genes with putative tumor suppressor activity, as demonstrated by loss of heterozygosity in both the EXT1 region on chromosome 8 and the EXT2 region on chromosome 11 in chondrosarcomas (Raskind et al. 1995; Hecht et al. 1997). Recent lines of evidence suggest that EXT1 and EXT2 are glycosyltransferases required for the biosynthesis of heparan sulfate (McCormick et al. 1998; Lind et al. 1998).

In addition to the EXT1 and EXT2 genes, three other homologous genes belonging to the EXT gene family, EXTL1 (Wise et al. 1997), EXTL2 (Wuyts et al. 1997), and EXTL3 (Van Hul et al. 1998) have been cloned through 
homology searches with expressed sequence tags (ESTs). So far, germline mutation in EXTL genes has not been identified in EXT patients.

Since the cloning of the EXT1 and EXT2 genes, there have been a few reports describing the germline mutation screening of these genes in EXT families (Ahn et al. 1995; Hecht et al. 1997; Philippe et al. 1997; Raskind et al. 1998; Stickens et al. 1996; Wells et al. 1997; Wuyts et al. 1996; Wuyts et al. 1998).

In this article, we report the mutation screening of $E X T 1$ and EXT2 in eight unrelated Korean EXT families by polymerase chain reaction-single strand conformation polymorphism (PCR-SSCP) analysis followed by direct DNA sequencing.

\section{Subjects, materials, and methods}

\section{DNA isolation from blood samples}

Blood samples and clinical information on eight unrelated Korean EXT families were obtained from the Korean Hereditary Tumor Registry, at the Seoul National University College of Medicine. All families had two or more members affected with EXT. Informed consent was obtained from all patients prior to blood collection. Genomic DNA was prepared from peripheral blood, as described previously (Blin and Stafford 1976).

\section{Mutation screening of $E X T 1$ and $E X T 2$}

PCR and SSCP analysis was performed for all coding sequences of the EXT1 and EXT2 genes. The primer sequences used for PCR of EXT1 and EXT2 have been described previously (Philippe et al. 1997; Wells et al. 1997). DNA samples were PCR amplified prior to SSCP analysis under the following conditions: $94^{\circ} \mathrm{C}$ for $5 \mathrm{~min}$, followed by 35 cycles of $94^{\circ} \mathrm{C}$ for $30 \mathrm{~s}, 50^{\circ} \mathrm{C}-58^{\circ} \mathrm{C}$ for $30 \mathrm{~s}$ (depending on the annealing temperature for each primer pair), and $72^{\circ} \mathrm{C}$ for $30 \mathrm{~s}$, and a final elongation step at $72^{\circ} \mathrm{C}$ for $5 \mathrm{~min}$. Reaction mixtures in a total volume of $25 \mu \mathrm{l}$ contained the following: $50 \mathrm{ng}$ of DNA template, $0.4 \mathrm{M}$ each primer, $120 \mathrm{M}$ each dNTP, PCR buffer ( $10 \mathrm{mM}$ Tris, $50 \mathrm{mM} \mathrm{KCl}, 1.5 \mathrm{mM} \mathrm{MgCl}_{2}$, $0.001 \%$ gelatin) (Perkin Elmer Cetus, Foster City, CA, USA) $0.1 \mu \mathrm{Ci} / \mu 1^{32} \mathrm{P} \mathrm{dCTP}(3000 \mathrm{Ci} / \mathrm{mmol}$ ) (Amersham, Arlington Heights, IL, USA), and Taq DNA polymerase $0.01 \mathrm{U} / \mu \mathrm{l}$ (Perkin Elmer Cetus). After amplification, $15 \mu \mathrm{l}$ of the reaction mixture was diluted with $15 \mu \mathrm{l}$ of formamide dye (deionized formamide $95 \%, 10 \mathrm{mM}$ ethylene diamine tetraacetic acid [EDTA], $0.05 \%$ xylene cyanol, and $0.05 \%$ bromphenolblue). Samples were denatured at $95^{\circ} \mathrm{C}$ for $4 \mathrm{~min}$ and placed on ice prior to loading on SSCP gel. Four $\mu l$ of each reaction mixture was loaded into a $6 \%(48: 1$ acrylamide:bis) non-denaturing polyacrylamide gel. Electrophoresis was performed at $400 \mathrm{~V}$ constant voltage at $4^{\circ} \mathrm{C}$ for 13-16h. Gels were dried and exposed to Fuji RX film (Fuji Photo Film, Tokyo, Japan) for 12-24h.
DNA sequencing

When abnormal band patterns were detected by PCRSSCP analysis, the PCR products were purified with a QIAquick PCR purification kit (Quiagen, Chatsworth, CA, USA) and sequenced directly with a Taq dideoxy terminator cyclic kit on an ABI 377 automatic DNA sequencer (Perkin-Elmer).

For mutation analysis in the EXT2 gene by direct sequencing, exons 2 and 4 of EXT2 were amplified, and the resulting PCR products were ligated into the PCRTM-II vector and subcloned, using the TA cloning system (InVitrogen, San Diego, CA, USA). Several clones were sequenced directly with a Taq dideoxy terminator cyclic kit on an ABI 377 automatic DNA sequencer (Perkin-Elmer).

The sequences were analyzed visually by comparison of the mutated sequence with a sequence from a normal control.

\section{Results and discussion}

EXT1 is composed of 11 exons and EXT2 is composed of 16 exons and the flanking intronic sequences. In this study, we searched for germline mutations of the entire coding sequences of EXT1 and EXT2, excluding exons 1a and 1b of EXT2 encoding the 5'-untranslated region (UTR).

In one EXT family (SNU-OC3) with EXT-affected members through four generations (Fig. 1a), abnormal bands were detected after SSCP analysis of exon 5 of the EXT1 gene (Fig. 1b). The proband in this family was a 15year-old male with multiple exostoses involving the hip, knee, ankle, foot, elbow, scapula, shoulder, wrist, and hand. His father also had exostoses involving both knees. Sequencing of the exon 5 PCR product derived from the proband revealed a 10-base pair deletion at the $3^{\prime}$ end of exon 5 (CTAATTTAGg), including the donor splice site of intron 5 (Fig. 1c). The same mutation was also identified in the proband's father, confirming that this mutation cosegregated with the EXT phenotype in this family. We did not perform a detailed analysis of the consequences of this mutation. But since the mutation involves the conserved GT splicing junction at the $5^{\prime}$ end of intron 5, the mutation would result in improper splicing of this exon. The consequences of this mutation could possibly be intron 5 retention or exon 5 skipping, joining exon 4 to exon 6 , or use of the cryptic $5^{\prime}$ splice site. In either case, the most likely result would be premature translation termination, producing a truncated protein.

In the EXT2 gene, PCR-SSCP analysis did not reveal any abnormal band. This could be due to the limited sensitivity of SSCP, considering the fact that the sizes of the PCR products of $E X T 2$ varied from $253 \mathrm{bp}$ to $442 \mathrm{bp}$. So, we directly sequenced exons 2 and 4 of $E X T 2$, because $E X T 2$ mutations are more fequent in these exons (Wuyts et al. 1998). As a result, we were able to identify a missense mutation in the SNU-OC15 family (Fig. 2a,b). In this family, the proband was a 5-year-old boy with exostoses on both 
II

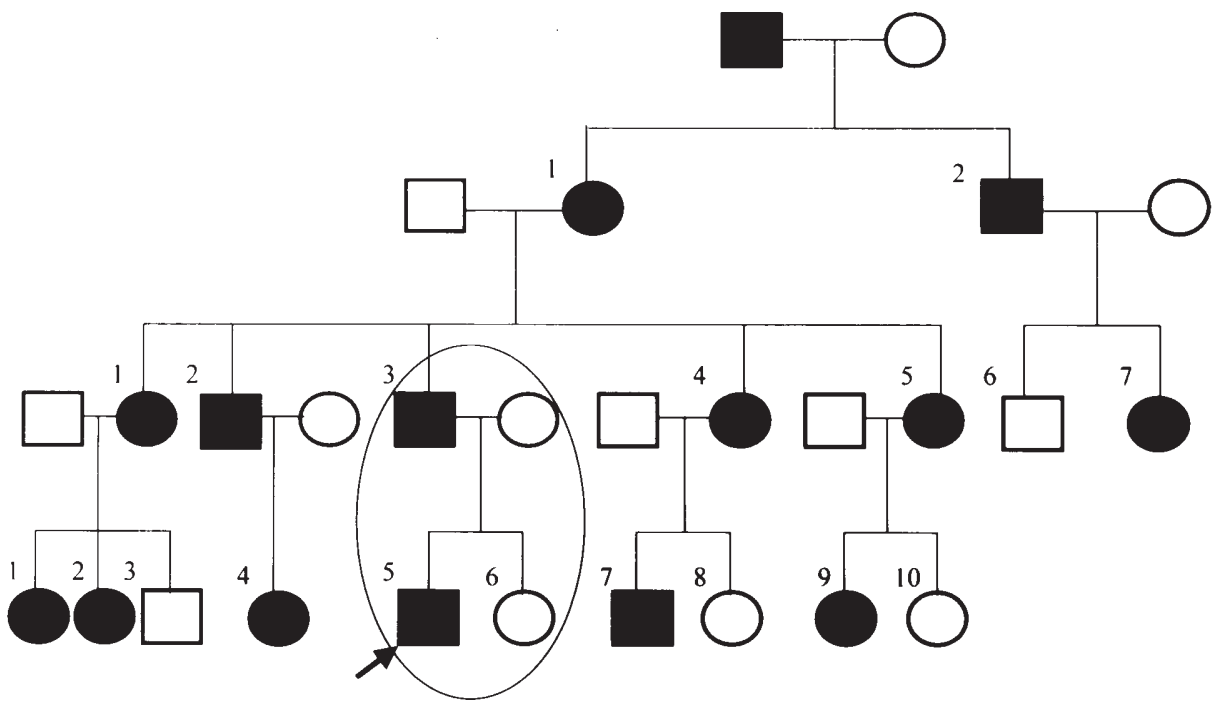

\title{
Normal
}

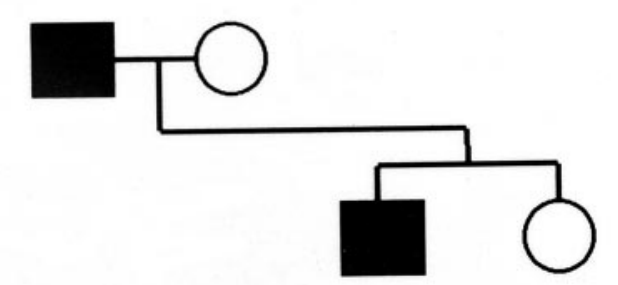

CTACTATG CTAATTTAGG TAAGT

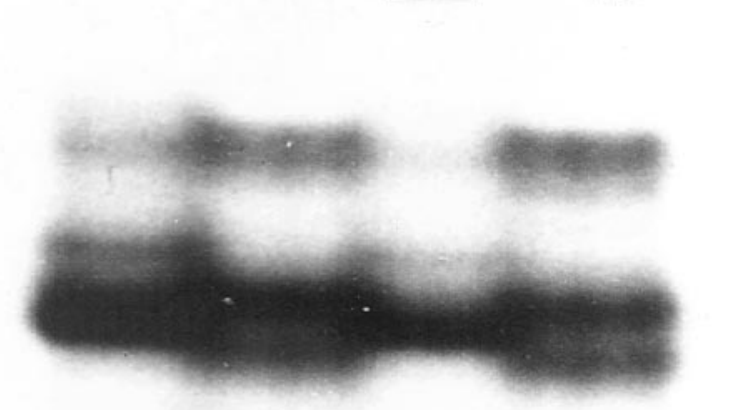

\section{SNU-OC3}

\author{
CTACTATG YWARK WWWKK YMWS
}
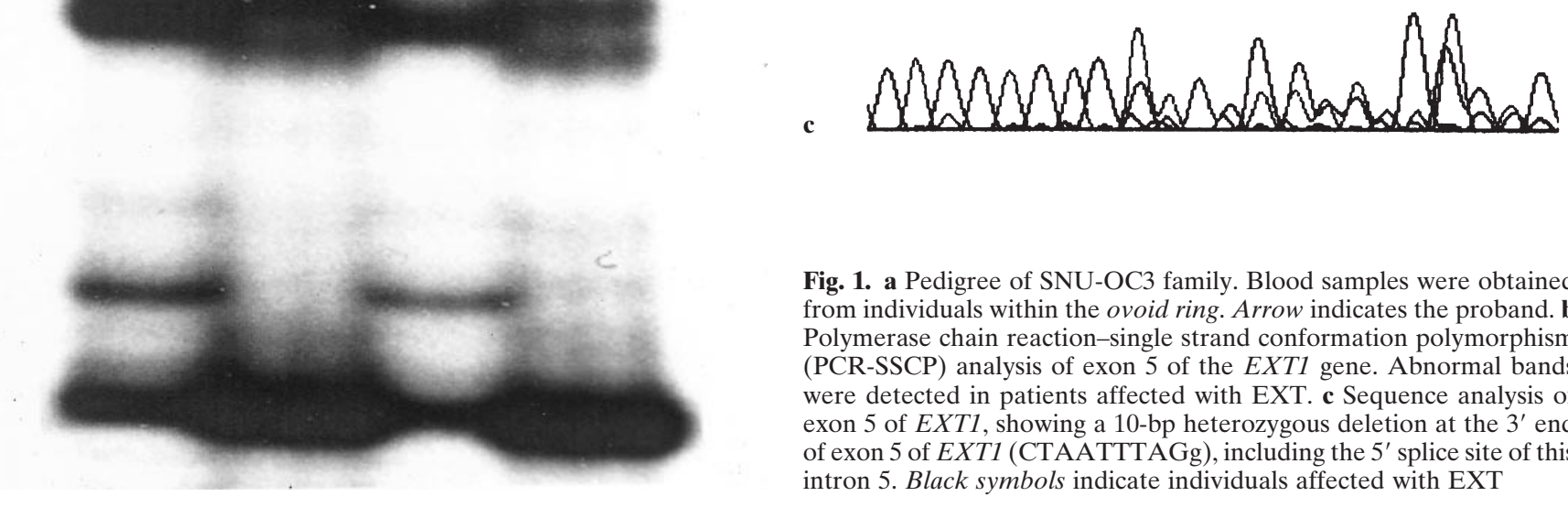

Fig. 1. a Pedigree of SNU-OC3 family. Blood samples were obtained from individuals within the ovoid ring. Arrow indicates the proband. b Polymerase chain reaction-single strand conformation polymorphism (PCR-SSCP) analysis of exon 5 of the EXT1 gene. Abnormal bands were detected in patients affected with EXT. c Sequence analysis of exon 5 of $E X T 1$, showing a 10-bp heterozygous deletion at the $3^{\prime}$ end of exon 5 of EXT1 (CTAATTTAGg), including the 5' splice site of this intron 5. Black symbols indicate individuals affected with EXT

legs (femur, tibia), both arms (radius, ulna, humerus), and both feet (proximal phalanges). His mother also had exostoses in both knees. Sequence analysis showed that the proband had a germline missense mutation ( $\underline{T} G C \rightarrow \underline{\text { CGC) }}$ at codon 85 of the EXT2 gene, leading to a cysteine-toarginine substitution. The same missense mutation was identified in the proband's mother. To confirm that the identified mutation was the disease-causing one, we sequenced exon 2 of EXT2 from six normal (without exostoses phenotype) family members, including the younger sister of the proband and three maternal aunts and two uncles. In the rest of the family members, the mutation 


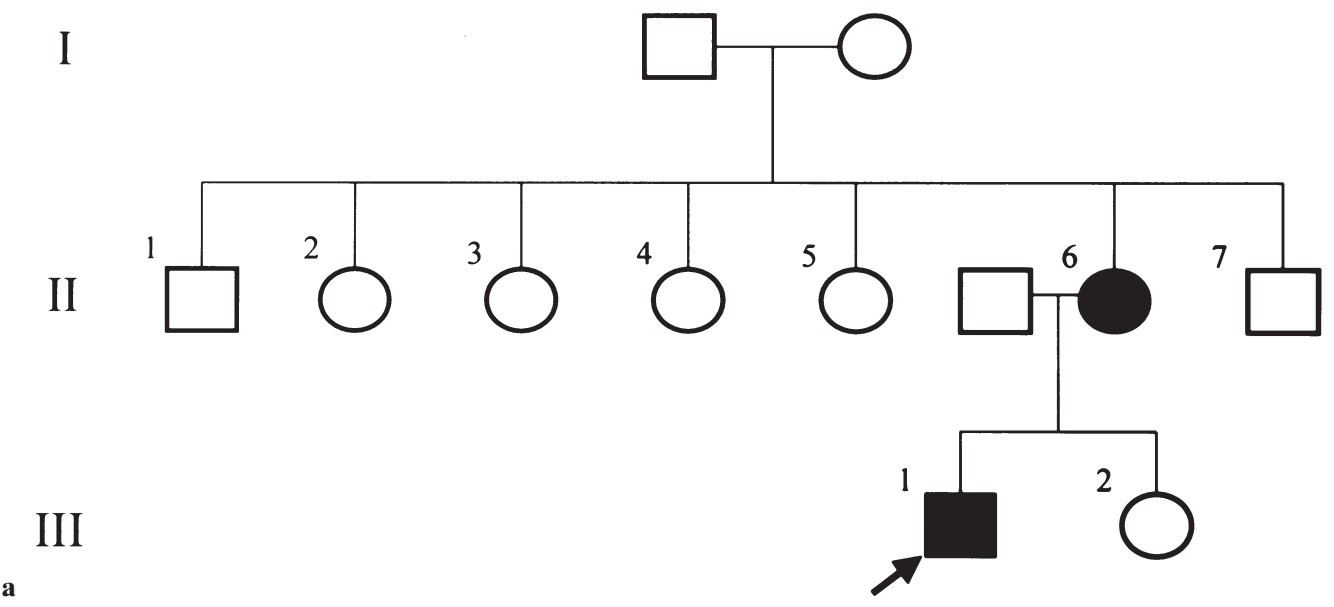
Normal
codon 85, Cys
GCGGGGGGAT CT CAGT TA CAATG

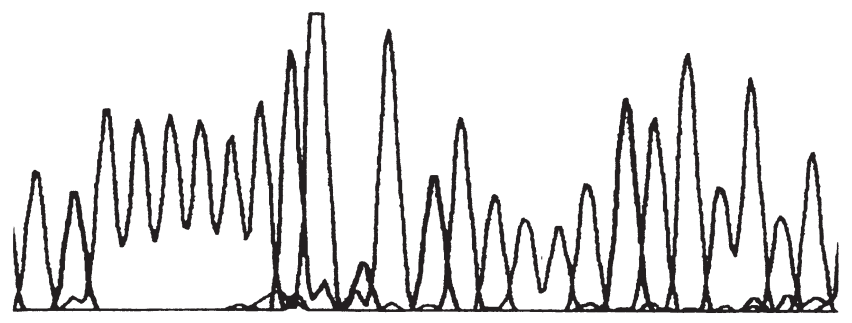

\section{SNU-OC15}

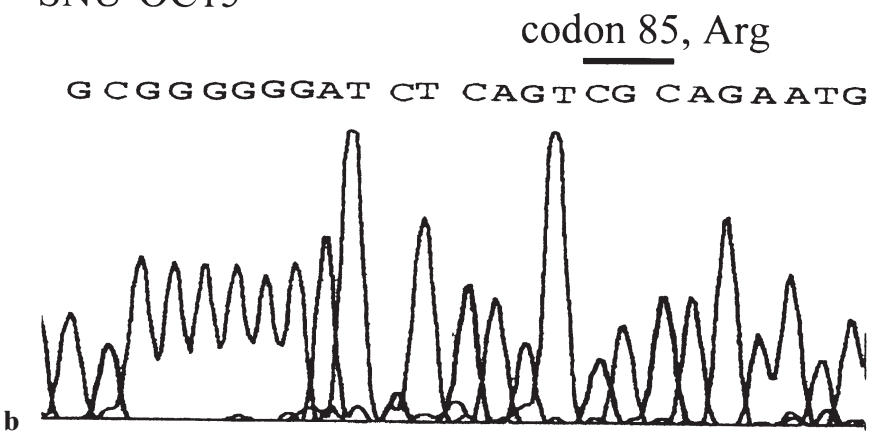

identified in the proband and his mother could not be identified. Thus, the missense mutation identified cosegregated with the exostoses phenotype, suggesting that the mutation is the disease-causing one. Direct sequencing of 100 control chromosomes from unrelated and unaffected normal individuals did not reveal this missense mutation, thus excluding the possibility of a rare polymorphism,

Analysis of EXT pedigrees has revealed that most are associated with EXT1 and EXT2 (Halloran-Blanton et al. 1996; Raskind et al. 1998), with EXT3 probably playing only a minor role. Our results provide further support for EXT1 and EXT2 genes being involved in EXT.

There have been 35 different $E X T 1$ mutations described in 43 families, and 12 different $E X T 2$ mutations described in 16 families (Wuyts et al. 1998; Raskind et al. 1998). All of these mutations have been found in families from Western countries. Seventy-seven percent of the mutations identi-
Fig. 2. a Pedigree of SNU-OC 15 family. There were only two individuals affected with EXT in this family. Arrow indicates the proband. b Sequence analysis of exon 2 of $E X T 2$ revealed a missense mutation

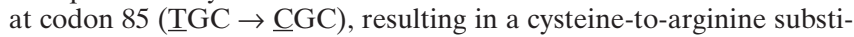
tution. This missense mutation cosegregated with the disease phenotype in this family, suggesting that this mutation is the cause of EXT

fied in the EXT1 gene are nonsense mutations, splice-site mutations, or frameshift mutations, which cause premature termination of the EXT1 protein (Wuyts et al. 1998). The consequence of the mutation identified in our SNU-OC15 family (10-base pair deletion at the $3^{\prime}$ end of exon 5, including the splice donor site of intron 5) is unknown. But since the deletion involves the conserved GT splicing junction at the $5^{\prime}$ end of intron 5, it is likely that the mutation would result in improper splicing of this exon with production of a truncated $E X T 1$ protein. However, there is also a possibility that the mutation may result in a frameshift.

Of the 12 EXT2 mutations reported thus far (Wuyts et al. 1998), 11 are nonsense mutations, splice-site mutations, or frameshift mutations, which cause premature termination of EXT2 protein (Wuyts et al. 1998). There has only been one missense mutation, described in two families at exon 4 of the EXT2 gene (Philippe et al. 1997). The 
missense mutation identified in our family (SNU-OC15) was at codon 85 of exon 2 of the EXT2 gene, with a resultant amino acid change from cysteine to arginine. Since this mutation cosegregated with the EXT phenotype in this family and since the same mutation was not identified in 100 chromosomes from an unrelated unaffected normal population, there is a high likelihood that this mutation is the disease-causing one. If this is the case, codon 85 of EXT2 may be an important domain for the proper function of the EXT2 protein.

The mutations identified in the EXT1 and EXT2 genes from our EXT families are novel ones, and extend the germline mutation spectrum identified in EXT.

Acknowledgments This work was supported by grants from the 19951997 Good Health R and D Project, the Ministry of Health and Welfare of the Republic of Korea, and from the Korea Science and Engineering Foundation (KOSEF) through the Cancer Research Center at the Seoul National University (KOSEF-CRC-97-8).

\section{References}

Ahn J, Ludecke HJ, Lindow S, Horton WA, Lee B, Wagner MJ, Horsthemke B, Wells DE (1995) Cloning of the putative tumor suppressor gene for hereditary multiple exostoses (EXT1). Nat Genet 11:137-143

Blin N, Stafford DM (1976) A general method for isolaton of high molecular weight DNA from eukaryotes. Nucleic Acids Res 3:2303-2308

Cooke A, Raskind W, Blanton SH, Pauli RM, Gregg RG, Francomano CA, Puffenberger E, Conrad EJ, Schmale G, Schellenberg G, Wijsman E, Hecht JT, Wells DE, Wagner MJ (1993) Genetic heterogeneity in families with hereditary multiple exostoses. Am J Hum Genet 53:71-79

Halloran Blanton S, Hogue D, Wagner M, Wells D, Young ID, Hecht JT (1996) Hereditary multiple exostoses: confirmation of linkage to chromosomes 8 and 11. Am J Med Genet 62:150-159

Hecht JT, Hogue D, Wang Y, Blanton S, Wagner M, Strong LC, Raskind W, Hansen MF, Wells D (1997) Hereditary multiple exostoses: mutational studies of familial EXT1 cases and EXT-associated malignancies. Am J Hum Genet 60:80-86

Le Merrer M, Legeai-Mallet L, Margaritte-Jeannin P, Horsthemke B, Schinzel A, Plauchu H, Toutain A, Achard F, Munnich A, Maroteaux P (1994) A gene for hereditary multiple exostoses maps to chromosome 19. Hum Mol Genet 3:717-722

Lind T, Tufaro F, McCormick C, Lindahl U, Lindholt K (1998) The putative tumor suppressors EXT1 and EXT2 are glycosyltransferases required for biosynthesis of heparan sulfate. J Biol Chem 273:26265-26268

McCormick C, Ludec Y, Martindale D, Mattison K, Esford LE, Dyer AP, Tufaro F (1998) The putative tumor suppressor EXT1 alters the expression of cell-surface heparan sulfate. Nat Genet 19:158-161
Philippe C, Porter DE, Emerton ME, Wells DE, Hamish A, Simpson RW, Monaco AP (1997) Mutational screening of the EXT1 and EXT2 genes in patients with hereditary multiple exostoses. Am J Hum Genet 61:520-528

Raskind WH, Conrad EU, Chansky H, Matsushita M (1995) Loss of heterozygosity in chondrosarcomas for markers linked to hereditary multiple exostoses loci on chromosomes 8 and 11. Am J Hum Genet 56:1132-1139

Raskind WH, Conrad E, Matsushita M, Wijsman EM, Wells DE, Chapman N, Sandell LJ, Wagner M, Houck J (1998) Evaluation of locus heterogeneity and EXT1 mutations in 34 families with hereditary multiple exostoses. Hum Mut 11:231-239

Schmale GA, Conrad EU, Raskind WH (1994) The natural history of hereditary multiple exostoses. J Bone Joint Surg 76:986-992

Solomon L (1963) Hereditary multiple exostoses. J Bone Joint Surg 45:292-304

Stickens D, Clines G, Burbee D, Ramos P, Thomas S, Hogue D, Hecht JT, Lovett M, Evans GA (1996) The EXT2 multiple exostoses gene defines a family of putative tumor suppressor genes. Nat Genet $14: 25-32$

Van Hul W, Wuyts W, Hendrickx J, Speleman F, Wauters J, De Boulle K, Van Roy N, Bossuyt P, Willems PJ (1998) Identification of a third EXT-like gene (EXTL3) belonging to the EXT gene family. Genomics 47:230-237

Wells DE, Hill A, Lin X, Ahn J, Brown N, Wagner MJ (1997) Identification of novel mutations in the human EXT1 tumor suppressor gene. Hum Genet 99:612-615

Wicklund CL, Pauli RM, Johnston D, Hecht JT (1995) Natural history of hereditary multiple exostoses. Am J Hum Genet 55:43-46

Wise CA, Clines GA, Massa H, Trask BJ, Lovett M (1997) Identification and localization of the gene for EXTL, a third member of the multiple exostoses gene family. Genome Res 7:10-16

Wu Y, Heutink P, de Vries B, Sandkuijl LA, van den Ouweland AMW, Niermeijer MF, Galjaard H, Reyniers E, Wilems PJ, Halley DJJ (1994) Assignment of a second locus for multiple exostoses to the pericentromeric region of chromosome 11. Hum Mol Genet 3:167171

Wuyts W, Ramlakhan S, Van Hul W, Hecht JT, van den Ouweland AMW, Raskind WH, Hofstede FC, Reyners E, Wells DE, de Vries B, Conrad EU, Hill A, Zalatayev D, Weissenbach J, Wagner MJ, Bakker E, Halley DJJ, Willems PJ (1995) Refinement of the multiple exostoses locus ( $E X T 2)$ to a 3-cM interval on chromosome 11. Am J Hum Genet 57:382-387

Wuyts W, Van Hul W, Wauters J, Memtsova M, Reyners E, Van Hul E, De Boulle K, de Vries BBA, Hendrickx J, Herrygers I, Bossuyt P, Balemans W, Fransen E, Vits L, Coucke P, Nowak NJ, Shows TB, Mallet L, van den Ouweland AMW, McGaughran J, Halley DJJ, Willems PJ (1996) Positional cloning of a gene involved in hereditary multiple exostoses. Hum Mol Genet 10:1547-1557

Wuyts W, Van Hul W, Hendrikx J, Speleman F, Wauters J, De Boulle K, Van Roy N, Van Agtmael T, Bossuyt P, Willems PJ (1997) Identification and characterization of a novel member of the EXT gene family, EXTL2. Eur J Hum Genet 5:382-389

Wuyts W, Van Hul W, De Boulle K, Hendrikx J, Bakker E, Vanhoenacker F, Mollica F, Ludecke HJ, Sayli BS, Pazzaglia UE, Mortier G, Hamel B, Conrad EU, Matsushita M, Raskind W, Willems P (1998) Mutations in the EXT1 and EXT2 genes in hereditary multiple exostoses. Am J Hum Genet 62:346-354 